\title{
COMPORTAMENTO MECÂNICO DE NANOCOMPÓSITOS NANOTUBO DE CARBONO/POLIETILENO
}

\author{
F. V. FERREIRA ${ }^{1}$, W. FRANCISCO ${ }^{1}$, E. V. FERREIRA ${ }^{2}$, L. S. CIVIDANES ${ }^{1}$ A. R. \\ COUTINHO $^{3}$ e G. P. THIM ${ }^{1}$ \\ ${ }^{1}$ Instituto Tecnológico de Aeronáutica, Divisão de Ciências Fundamentais \\ ${ }^{2}$ Universidade Federal de Juiz de Fora, Departamento de Estatística \\ ${ }^{3}$ Universidade Metodista de Piracicaba, Faculdade de Engenharia Arquitetura e Urbanismo \\ E-mail para contato: filipevargasf@hotmail.com
}

\begin{abstract}
RESUMO - Nanocompósitos de polietileno de alta densidade (PEAD) e nanotubos de carbono (CNT) foram preparados através de mistura com agitação mecânica do polímero fundido, e moldadas por compressão. A quantidade de CNT e a temperatura de dispersão $\mathrm{PEAD/CNT}$ foram determinadas usando Planejamento Composto Central cuja resposta foi a microdureza dos nanocompósitos. A quantidade de CNT foi avaliada em uma faixa de 0,1 a $2,1 \%$, e a temperatura de dispersão em uma faixa de 25 a $90{ }^{\circ} \mathrm{C}$. Os resultados mostraram que o nanotubo de carbono influencia significativamente na microdureza dos compósitos. Já a temperatura de dispersão interfere significativamente na sua homogeneidade. Foi proposta uma equação que melhor representa o sistema, através da qual foi determinado o ponto ótimo para porcentagem de CNT $(0,8 \%)$ e temperatura de dispersão $\left(55^{\circ} \mathrm{C}\right)$.
\end{abstract}

\section{INTRODUÇÃO}

O nanotubo de carbono (CNT) está no topo da nanociência e nanotecnologia pelas suas notáveis propriedades elétricas, térmicas e mecânicas (Cividanes et al., 2012). Possui uma estrutura única, e devido as suas ligações covalentes $s p^{2}$, é considerado o material mais rígido e forte já conhecido (Hou et al., 2008; Linga et al., 2014). Por estas características apresenta grande potencial para ser utilizado como fase reforço em compósitos poliméricos, podendo ser aplicados nas áreas química (Jiang et al., 2014), física (Olneya et al., 2014), médica (Hashida et al., 2014), aeroespacial (Gohardan et al., 2012), automotiva (Presting e Koning, 2003), eletrônica (Li et al., 2010), dentre outras.

No entanto, para se alcançar um efetivo papel de reforço nos compósitos, dois aspectos devem ser levados em consideração: (i) a quantidade de nanotubo utilizada e (ii) sua homogênea dispersão na matriz polimérica. (i) Adicionando pouco nanotubo de carbono, ele não faz o papel de reforço no compósito, e em grandes quantidades, os nanotubos se aglomeram dificultando a transferência de carga da interface CNT/polímero. (ii) Já o estado de dispersão envolve interações competitivas que ainda não foram explicadas plenamente: interações do tipo força de Van der Waals entre os nanotubos, além da atração entre o nanotubo e a matriz polimérica (Maksimkin et al., 2012). Ainda neste contexto, o efeito da adição de CNT na microdureza do compósito também não está bem estabelecido na literatura. 
Diante do grande número de aplicações dos nanocompósitos, várias questões importantes relacionadas com suas propriedades devem ser esclarecidas, e a sua melhor compreensão vai ajudar a definir a relação estrutura/propriedade, para posteriormente relaciona-la com o produto final. (Kim et al, 2012;. Aravind et al., 2011).

\section{EXPERIMENTAL}

\subsection{Preparação dos compósitos polietileno/CNT}

Uma quantidade de nanotubo de carbono (avaliada em uma faixa de 0,1 a 2,1\%) foi sonificada em ultrassom de banho (Branson 2210, potência de $125 \mathrm{~W}$ ) com $10 \mathrm{ml}$ de acetona por 20 minutos. Em seguida, adicionou-se $8 \mathrm{~g}$ de grânulos de polietileno de alta densidade (PEAD) (IG58, Braskem: índice de fluidez de $50 \mathrm{~g} / 10 \mathrm{~min}$; densidade $=0,956 \mathrm{~g} / \mathrm{cm}^{3}$ ). A mistura foi então agitada magneticamente $(300 \mathrm{rpm})$ por 30 minutos, com temperatura de dispersão controlada (em uma faixa de 25 a $90{ }^{\circ} \mathrm{C}$ ). Logo após, a amostra foi degaseificada em estufa a $80^{\circ} \mathrm{C}$ por 4 dias. Após a degaseificação, a amostra de polietileno sólido/CNT foi colocada em estufa a $200{ }^{\circ} \mathrm{C}$ para a fusão do polietileno. Fundiu-se o polietileno a $200{ }^{\circ} \mathrm{C}$ por 30 minutos. Em seguida, a amostra de polietileno fundido/CNT foi agitada mecanicamente (200 rpm). Terminado este período, colocou-se manualmente a amostra de polietileno/CNT no molde (com $3 \mathrm{~mm}$ de espessura e $40 \mathrm{~mm}$ de raio) pré-aquecido a $200{ }^{\circ} \mathrm{C}$. A fim de evitar bolhas, o conjunto molde/amostra foi colocado em estufa a vácuo, a $200{ }^{\circ} \mathrm{C}$, por 20 minutos. Por fim, resfriou-se a amostra em temperatura ambiente. As variáveis \%CNT e temperatura de dispersão foram estudados seguindo um Planejamento Composto Central (Bruns et al., 1995) tendo como resposta a microdureza dos nanocompósito. Para cada variável independente atribuiu-se três níveis, inferior $(-1)$, central $(0)$ e superior $(+1)$. A porcentagem de CNT foi avaliada em uma faixa de 0,1 a 2,1\% (percentual em massa de CNT no nanocompósito), e a variável temperatura de dispersão em uma faixa de 25 a $90{ }^{\circ} \mathrm{C}$.

\subsection{Caracterização}

A microdureza das amostras foi analisada em um equipamento Microdurômetro Tester FM-700, com carga de $50 \mathrm{~g}$ atuando por um tempo de 30 segundos. A dispersão do CNT na matriz polimérica foi avaliada pelas análises de microdureza. Foram realizadas 32 medidas em cada um dos corpos de prova; quanto menor a variabilidade das observações de microdureza, mais disperso está o nanotubo de carbono no polímero.

\section{RESULTADOS E DICUSSÕES}

Foram realizadas 32 medidas de microdureza em cada um dos corpos de prova. Admitiu-se a normalidade dos dados (p-valor $<0,001$, Figura 1). As análises estatísticas foram baseadas em testes de hipótese de igualdade das médias e igualdade das variâncias (nível de significância de 5\%), e desenvolvidas no ambiente computacional, gráfico e estatístico R (R Development Core Team, 2012) e Statistica (Statsoft, v.6.0, 2011).

Figura 1 - Gráficos normais de probabilidades para três cenários estudados 

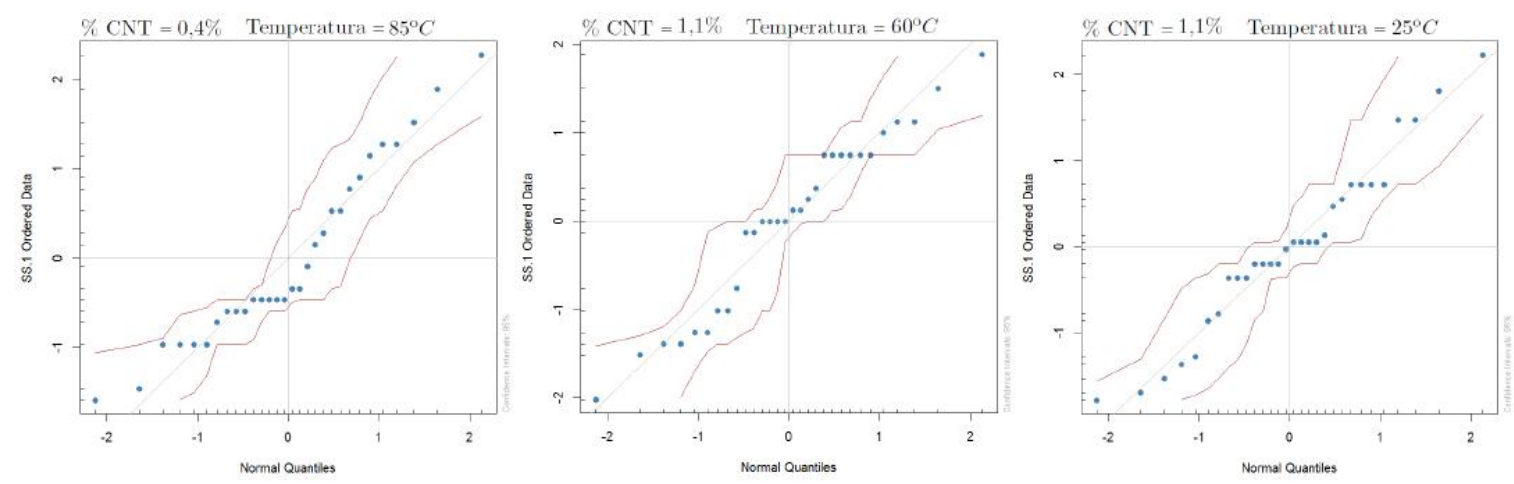

Na Figura 2 é apresentado o Box-plot das 32 medidas de microdureza. Analisando inicialmente os ensaios 1 e 2, nota-se que a mudança da temperatura de 35 para $85{ }^{\circ} \mathrm{C}$, mantendo fixo a \%CNT $=0,4$, provoca uma diferença (aumento) na variabilidade de microdureza ( $\mathrm{p}$-valor $<0,001)$. Além disso, verifica-se que, em média, seu valor decresce de 6,42 para 5,57 HV (p-valor $<0,001$ ). Comportamento semelhante ao encontrado nos ensaios 3 e 4, em que a mudança na temperatura acarretou o aumento da variabilidade das observações, bem como o valor médio de microdureza (de 5,58 para 7,32 HV; p-valor $<0,001$ ). Tais resultados sugerem que a temperatura interfere significativamente na dispersão do CNT no polímero, deixando a amostra menos homogênea.

Figura 2 - Box-plot de microdureza sob diferentes \%CNT e temperatura de dispersão

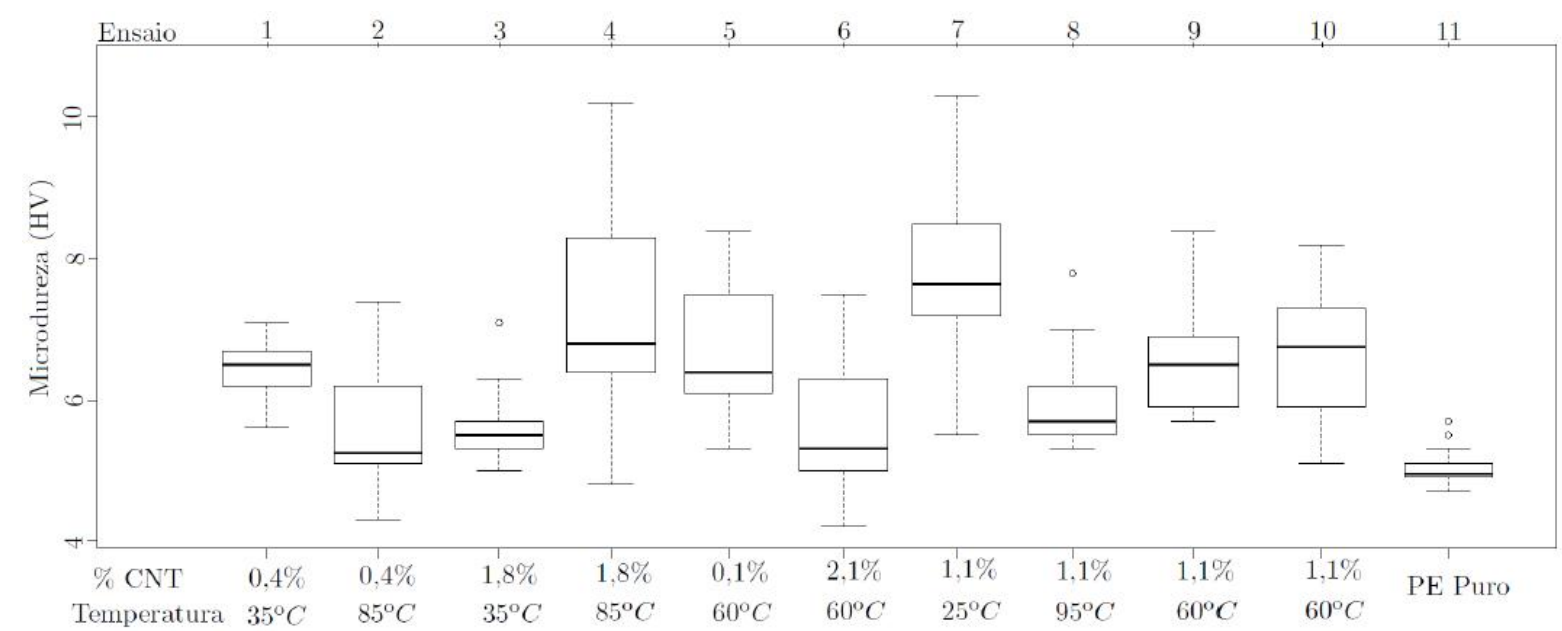

Avaliando a \%CNT e mantendo fixa a temperatura (ensaios 1 e 3 ), verifica-se que ao adicionar nanotubo ao polietileno a microdureza média das amostras diminui de 6,42 para $5,58 \mathrm{HV}$ (p-valor < 0,001); não alterando, todavia, sua variabilidade ( $\mathrm{p}$-valor $=0,703$ ). Comportamento semelhante ao observado nos ensaios 5 e 6 , com médias de microdureza de 5,54 e 6,74 HV, respectivamente, rejeitando a hipótese de igualdade dessas médias (p-valor $<0,001$ ). Este fato sugere que o nanotubo pode auxiliar na microdureza em determinadas condições (analisadas a posteriori), mas pode também prejudicar, dependendo do seu percentual no compósito.

Finalmente, pode-se concluir que os ensaios que apresentaram maior microdureza média foram os ensaios 4 e 7, apresentando valores de 7,32 e 7,63 HV, respectivamente 


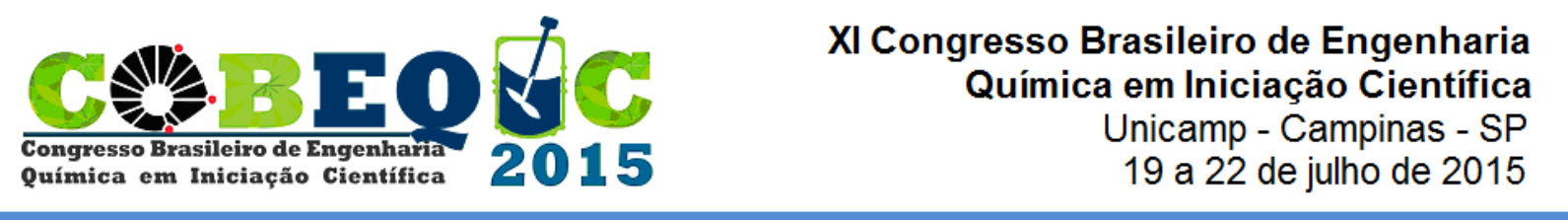

(valores estatisticamente iguais; $p$-valor $=0,42$ ). No entanto, o ensaio 7 apresentou menor variabilidade.

Na Figura 3 é apresentado o gráfico de superfície para a microdureza. Pela sua análise, nota-se que o comportamento da porcentagem de CNT e temperatura de dispersão não são lineares, ou seja, existe um ponto de inflexão entre os extremos. Isso ocorre, pois a variável porcentagem de CNT, quando em excesso, dificulta a homogeneização dos corpos de prova, prejudicando a estabilização dos nanotubos no compósito, e, em pequenas quantidades, não exerce o papel de reforço. Este comportamento também foi observado por autores como Ruana et al. (2003) e Guedes et al. (2013). Já a variável temperatura de dispersão pode influenciar nas propriedades dos compósitos em dois aspectos: (1) a temperatura ideal para reação de acoplamento entre o CNT e a matriz polimérica não deve acontecer em temperaturas muito baixas (Na et al., 2010). (2) Por outro lado, em temperaturas elevadas a acetona será rapidamente vaporizada e incapaz de dispersar os nanotubos no PEAD (devido a sua taxa de volatilização). Desta forma, é razoável a ideia de que em temperaturas intermediárias haja um bom acoplamento PEAD/CNT, favorecendo assim a transferência de carga entre as superfícies, bem como uma uniforme dispersão dos nanotubos no compósito.

Figura 3 - Superfície de resposta para microdureza em função da \%CNT e temperatura de dispersão
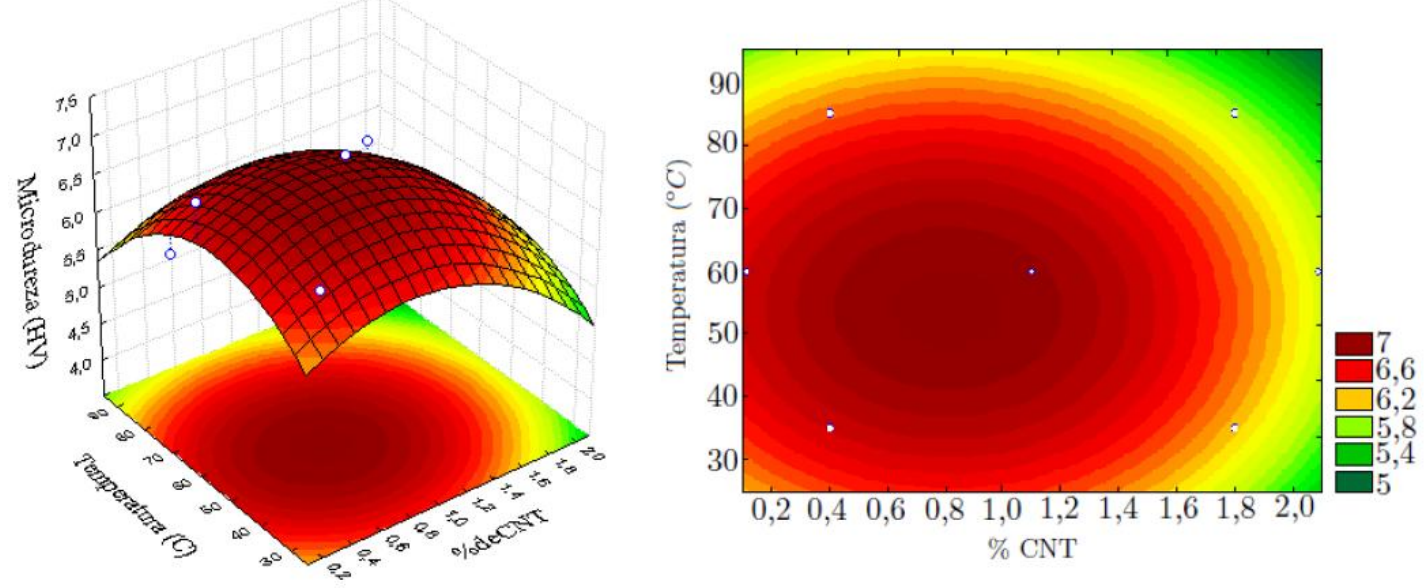

Após análise do gráfico de superfície propôs-se a equação que melhor representa o sistema (Equação 1), apresentada como segue

$$
y(C, T)=5,336-0,825 x_{C}^{2}-0,001 x_{t}^{2}+1,332 x_{C}+0,083 x_{T}
$$

em que $\mathrm{x}_{\mathrm{C}}$ representa a porcentagem de $\mathrm{CNT}$; $\mathrm{x}_{\mathrm{T}}$ representa a temperatura de dispersão.

A partir da maximização da Equação 1, o ponto ótimo da porcentagem de CNT e da temperatura de dispersão é 0,8 e $55^{\circ} \mathrm{C}$, respectivamente.

\section{CONCLUSÃO}


Pela análise da microdureza, observou-se que ambas as variáveis: porcentagem de CNT e temperatura de dispersão influenciam na microdureza. A temperatura de dispersão interfere na dispersão do nanotubo na matriz polimérica (homogeneidade das amostras). Já a \%CNT auxilia no aumento da microdureza, não alterando, contudo, a variabilidade dos compósitos. Ainda neste contexto, pela maximização da superfície de resposta, pode-se obter o ponto ótimo para a \%CNT $(0,8 \%)$ e temperatura de dispersão $\left(55^{\circ} \mathrm{C}\right)$.

\section{AGRADECIMENTO}

Os autores agradecem a FAPESP (processo $n^{0}$ 2013/20218-0) e CNPq pelo suporte, e ao LAS/INPE pela colaboração.

\section{REFERÊNCIAS}

BOURBIGOT, S.; DEVAUX, E.; FLAMBARD, X. Flammability of polyamide-6/clay hybrid nanocomposite textiles. Polymer Degradation and Stability., V.75, p. 397-402, 2002.

BRUNS, R.; BARROS NETO, B.; SCARMINIO, J. Planejamento e otimização de experimentos. Campinas- SP: Editora Unicamp, 1995.

CIVIDANES, L.; BRUNELLI, D.; ANTUNES, E.; CORAT, E.; SAKANE, K.; THIM, G. Cure study of epoxy resin reinforced with multiwalled carbon nanotubes by raman and luminescence spectroscopy. Journal of Applied Polymer Science., v.27,p. 544-553, 2012.

GUEDES, R.; PEREIRA, C.; FONSECA, A.; OLIVEIRA, M. The effect of carbon nanotubes on viscoelastic behaviour of biomedical grade ultra-high molecular weight polyethylene. Composite Structures., v.105, p. 263-268, 2013.

GOHARDAN, O.; WILLIAMSON, D.; HAMMOND, D. Multiple liquid impacts on polymeric matrix composites reinforced with carbon nanotubes. Wear., v. 294, p. 336-346, 2012.

HASHIDA, Y.; TANAKA, H.; ZHOU, S.; KAWAKAMI, S.; YAMASHITA, F.; MURAKAMI, T.; UMEYAMA, T.; HIMAHORI, H.; HASHIDA, M. Photothermal ablation of tumor cells using a single-walled carbon nanotube-peptide composite. Journal of Controlled Release., v.173, p. 59-66, 2014.

HOU, P.; LIU, C.; CHENG, H. Purification of carbon nanotubes. Carbon., v.46, p. 20032025, 2008.

IIJIMA, S. Helical microtubules of graphitic carbon. Nature (London)., v.354,p. 56-58, 1991. JANG, J.; PHAN, V.; HUR, S.H.; CHUNG, J. Dispersibility of reduced alkylaminefunctionalized graphene oxides in organic solvents. Journal of Colloid and Interface Science., v.424, p. 62-66, 2014.

LI, W.; JUNG, H.; HOA, N.; KIM, D.; HONG, S.; KIM, H. Nanocomposite of cobalt oxide nanocrystals and single-walled carbon nanotubes for a gas sensor application. Sensors and Actuators B., v.150, p. 160-166, 2010.

LINGA, X.; WEIA, Y.; ZOUA, L.; XU, S. Functionalization and dispersion of multiwalled carbon nanotubes modi_ed with poly-l-lysine. Colloids and Surfaces A: Physicochem. Eng. Aspects., v.443, p. 19-26, 2014.

MAKSIMKIN, A.; KALOSHKIN, S.; KALOSHKINA, M.; GORSHENKOV, M.; TCHERDYNTSEV, V.; ERGIN, K.; SHCHETININ, I. Ultra-high molecular weight polyethylene reinforced with multi-walled carbon nanotubes: Fabrication method and properties. Journal of Alloys and Compounds., v.536, p. 538-540, 2012. 
NA, X.; QINGJIE, J.; CHONGGUANG, Z.; CHENGLONG, W.; YUANYUAN, L. Study on dispersion and electrical property of multi-walled carbon nanotubes/low-density polyethylene nanocomposites. Materials and Design., v.31, p. 1676-1683, 2010.

OLNEYA, D.; FULLER, L.; SANTHANAM, K. A greenhouse gas silicon microchip sensor using a conducting composite with single walled carbon nanotubes. Sensors and Actuators B: Chemical., v.191, p. 545-552, 2014.

PLACKETT, R.L.; BURMAN, J.P. The design optimum multifactorial experiments. Biometrika., v.33, p. 305-325, 1946.

PRESTING, H.; KONIG, U. Future nanotechnology developments for automotive applications.Materials Science and Engineering C., v.23, p. 737-741, 2003.

R Development Core Team. A Language and Environment for Statistical Computing, 2012.

RUAN, S.; GAO, P.; YANG, X.; YU, T. Toughening high performance ultrahigh molecular weight polyethylene using multiwalled carbon nanotubes. Polymer., v.44, p. 5643-5654, 2003.

Statsoft. Software Statistica. Statsoft, v.6.0, 2011. 